\title{
Influence of tire inflating pressure at dynamic forces acting on articulated trolleybus
}

\author{
Pavel Polach ${ }^{1, *}$ \\ ${ }^{1}$ Výzkumný a zkušební ústav Plzeň s.r.o., 30100 Plzeň, Tylova 1581/46, Czech Republic
}

\begin{abstract}
KODA VÝZKUM s.r.o. cooperated on the development of the NEOPLAN DMA low-floor articulated trolleybus intended for the Boston city. Multibody models and finite element models of the trolleybus were utilized in the stage of the vehicle design. At the end of the stage of computer modelling and testing of the trolleybus prototype a decision to reduce tire inflating of vehicles in serial production (together with the change the type of shock absorbers used in trolleybus suspension) was made. The impact of this change on forces acting in the trolleybus suspension elements (i.e. in air springs and shock absorbers) and radius rods on the trolleybus chassis when running on an uneven test track was investigated using multibody simulations. Time histories of the forces calculated utilising multibody models were used as input data of the trolleybus finite element models.
\end{abstract}

\section{Introduction}

Optimum dynamic properties of a vehicle intended for public transport can usually be achieved by the proper chassis structural design including the used spring-damper elements (i.e. springs, shock absorbers, bushings and finally tires). The design must be the compromise of requirements for the vehicle behaviour during driving manoeuvres, for riding comfort, for the vehicle body and the chassis parts lifetime when driving on an uneven road surface and for the passengers' safety (e.g. [1]).

In 2003 Neoplan USA Corporation, the American producer of buses and trolleybuses, started to develop the NEOPLAN DMA low-floor articulated trolleybus intended for the city of Boston (see Fig. 1). ŠKODA VÝZKUM s.r.o. (now Výzkumný a zkušební ústav Plzen s.r.o.) cooperated on the development of the trolleybus. Multibody models and finite element (FE) models of the trolleybus were utilized in the stage of the trolleybus design. At the end of computer modelling and testing the trolleybus prototype a decision to reduce the tire inflating of vehicles in serial production (together with the change of the type of shock absorbers used in trolleybus suspension) was made because high stresses were calculated and measured in the trolleybus chassis in the place of the centre axle mounting during test drives on an uneven road surface. Lower tires inflating (100 psi instead of original $120 \mathrm{psi}$ ) results in their less steep radial force-deformation characteristics and their lower radial damping coefficient. On the one hand it leads to smaller stiffness of tires and on the other

${ }^{*}$ Corresponding author: polach@vzuplzen.cz 
hand to larger deflections of tires. The impact of this change on forces acting in the trolleybus suspension elements (i.e. in air springs and shock absorbers) and radius rods on the trolleybus chassis when running on an uneven test track was investigated using the multibody simulations. Time histories of the forces calculated using multibody models were then used as input data of the trolleybus FE models. Utilizing the trolleybus FE models created in the COSMOS/M software [2] the critical places of the trolleybus body structure from the point of view of high stresses were determined [3]. At the measurement on the real trolleybus prototype in these places there were measured stresses using strain gauges. The experimental measurement results were utilized for the confirmation of the stresses reducing.

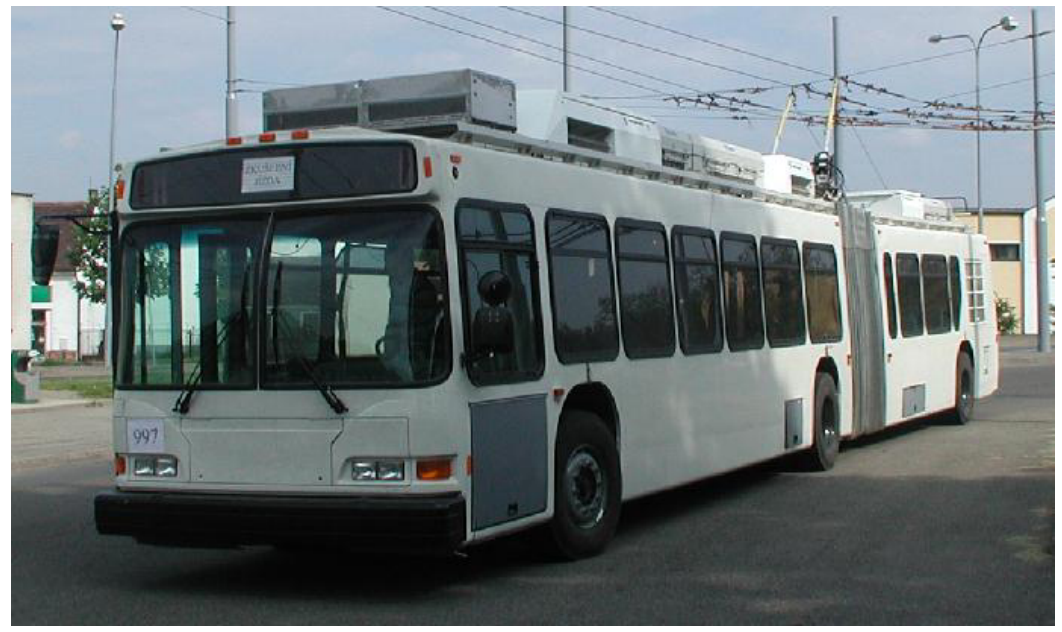

Fig. 1. The NEOPLAN DMA low-floor articulated trolleybus.

The influence of the already mentioned using shock absorbers of another type that have less steep force-velocity characteristics in rebound stage on forces acting in the trolleybus suspension elements is presented in $[4,5]$ - utilisation of another type of shock absorbers turned out to be suitable because maximum values of forces acting in the trolleybus suspension elements and radius rods decreased.

Generally, the assessment of vehicle's dynamic properties is related to three essential motions: longitudinal motion (driving and braking), lateral motion (guidance and steering) and vertical motion (suspension and damping) [6]. Driving on the uneven road surface can reveal many facts about the vehicle vertical dynamic properties and about the suitability of the used suspension elements of axles. Especially time histories of relative deflections of springs, relative velocities in the shock absorbers, stress acting in the axles' radius rods and/or radius arms and acceleration in various points in the vehicle interior are the monitored quantities [7]. On the basis of relative deflections of springs, relative velocities of shock absorbers and stresses acting in radius rods and/or radius arms it is possible to determine time histories and extreme values of the forces acting in the suspension elements of axles which can be utilized in connection with the suitable computational methods for the stress analysis of structures, for the prediction of the fatigue life of the body and the chassis parts of the tested vehicle (e.g. [8]).

Many professional books and papers deal with the investigation and approaches to the evaluation of vehicle dynamics using computer simulations. A smaller part of them is focused on the vehicles of public transport but despite this fact they are numerous. That is why a relevant literature is mentioned only in brief. The problematics of modelling vehicles in order to investigate their driving properties is globally solved e.g. in $[1,6,8,9]$. Global 
investigation of vehicle dynamics using computer simulations is dealt with e.g. in [10], where numerous quantities informing on the vehicle driving properties are monitored.

A good survey of literature dealing with vertical dynamics of public transport and heavy vehicles is given e.g. in [11] and the literature dealing with the optimization of suspension elements of those types of vehicles in [12]. E.g. Margolis and Edeal [13] created a 2 degreeof-freedom, small vertical motion bus frame model to which the engine, cab, and load were added in addition to suspension forces. Michelberger et al. [14] identified a discrete transfer function for a free-free beam model of a two-axis bus, and then estimated modal characteristics based on the measured data. The principal aim of paper [15] is to evaluate the feasibility of using gradient-based approximation methods for the optimization of the spring and damper characteristics of an off-road vehicle, for both ride comfort and handling. Eriksson and Friberg [16] optimized the linear spring and damper characteristics of the engine mounting system on a city bus for the ride comfort. Andersson and Eriksson [17] optimized the non-linear spring and damper characteristics of a full city bus vehicle model that was validated against test data. Kowarska et al. $[18,19]$ was engaged in virtual designing of the bus suspension elements.

\section{Multibody models of the trolleybus}

In order to obtain a tool for dynamic analysis (e.g. $[9,20])$ multibody models of an empty (21 tons weight) and a fully loaded (31 tons weight) NEOPLAN DMA low-floor articulated trolleybus were created [21] (see Fig. 2). The multibody models were created in the alaska 2.3 simulation tool [22].

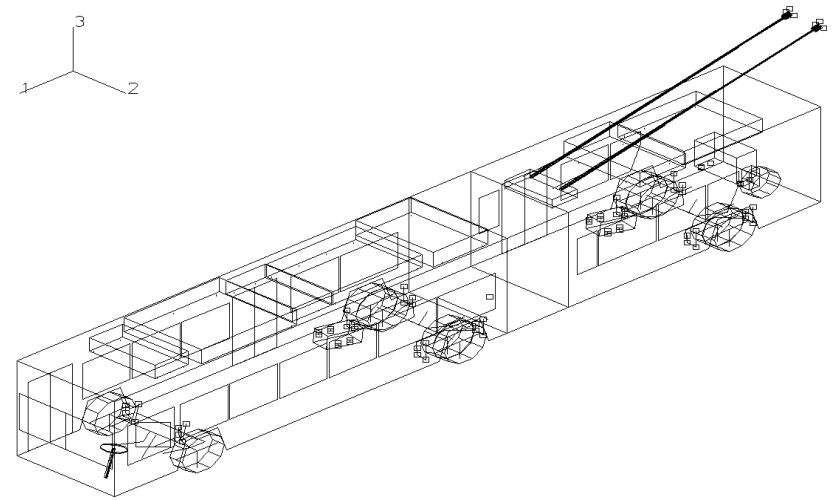

Fig. 2. Simple visualization of the NEOPLAN DMA trolleybus multibody model in the alaska 2.3 simulation tool.

The multibody models of the NEOPLAN DMA trolleybus are formed by 54 rigid bodies mutually coupled by 63 kinematic joints. The number of degrees of freedom of multibody models in kinematic joints is 164 . Kinematic scheme of the multibody models and sources of data used at multibody models creation are given in [21].

The rigid bodies correspond to the trolleybus individual structural parts and are defined by mass, centre of gravity coordinates and mass moments of inertia. Air springs and hydraulic shock absorbers in axles' suspension and bushings in the places of mounting certain trolleybus structural parts are modelled by connecting the corresponding bodies by nonlinear spring-damper elements. When simulating driving on an uneven road surface the contact point model of tires is used; radial stiffness and radial damping properties of tires are modelled by nonlinear spring-damper elements considering the possibility of the tire bounce from the road surface. 
Generally, the aim of the simulations with the multibody models of the NEOPLAN DMA low-floor articulated trolleybus is the determination of time histories or FFT results of time histories of monitored kinematic and dynamic quantities in the course of the chosen operational situation.

\section{Simulations}

As it has been already stated, the impact of changing the tire inflating on forces acting in the (empty) NEOPLAN DMA low-floor articulated trolleybus suspension elements and radius rods were investigated during the simulations of running on an uneven test track.

An uneven track test was carried out in the standard way according to the ŠKODA VÝZKUM road vehicles testing methodology (so called bump test; e.g. [5]). An artificial test track was created on a common bitumen road with a set of four portable standard bumps (according to the ČSN 300560 Czech Standard Obstacle II - see Fig. 3).

Vertical coordinates $z(x)$ of the standardized artificial obstacle are given by the formula

$$
z(x)=\sqrt{R^{2}-\left(x-\frac{d}{2}\right)^{2}}-(R-h),
$$

where $R=551 \mathrm{~mm}$ is the obstacle radius, $h=60 \mathrm{~mm}$ is the obstacle height, $d=500 \mathrm{~mm}$ is the obstacle length and $x$ is the obstacle coordinate in the vehicle driving direction [mm].

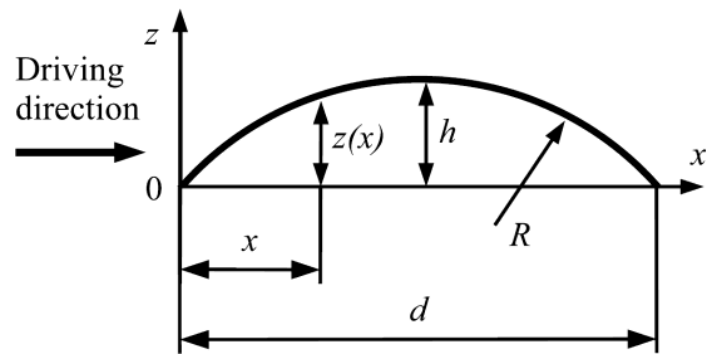

Fig. 3. The standardized artificial obstacle.

Artificial obstacles are spaced out on the smooth road surface 20 meters apart of a horizontal road. The first obstacle is run over only with right wheels, the second one with both and the third one only with left wheels (Fig. 4) at trolleybus speed $40 \mathrm{~km} / \mathrm{h}$. During the real NEOPLAN DMA trolleybus test the relative displacements between the axles and the chassis frame were measured (among others) and were compared with the results of the simulations with the multibody model [4].

The results of the simulations with the multibody model, i.e. the forces acting in the trolleybus suspension elements and radius rods on the trolleybus chassis, were used for dynamic calculation of the body structure stresses applying the finite element analysis (FEA).

Another reason for performing the bump test was the FEA model verification by measuring the stress-time histories at selected structural joints. The test results and/or its FEA simulation were also used for the preliminary evaluation of the critical joints fatigue life using design spectra. They represent the symmetrical loading cycles' histogram, the main parameters of which (maximum stress amplitude and predominant frequency of mechanical vibration) can be obtained from the bump test and the other ones can be derived from expected operational conditions. On the basis of empirical knowledge it is assumed that the maximum stress amplitudes at heavy damaged roads achieve from $80 \%$ to $100 \%$ of 
the bump test values. In the vehicle operation phase the design spectra can be compared with the real spectra and can be further modified.

MODE: RIGHT

BOTH

LEFT

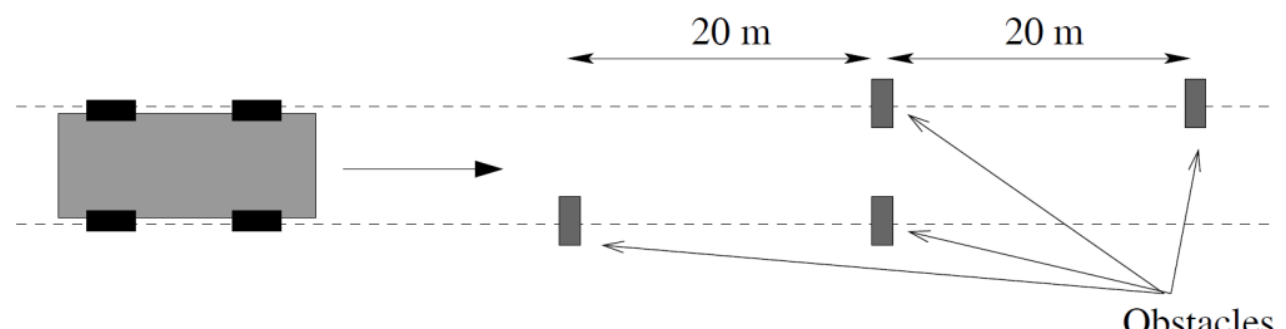

Fig. 4. Scheme of the track according to the ŠKODA VÝZKUM road vehicles testing methodology.

\section{Results}

Forces acting in axles' suspension elements and axial forces acting in axles' radius rods of the NEOPLAN DMA low-floor articulated trolleybus were the monitored quantities at simulations with the trolleybus multibody model.

Only the monitored quantities on the right side of the trolleybus and at running over the standardized obstacle with the right wheels are presented in this paper (just as at examining the influence on the change of the type of shock absorbers in [5]). It is given especially by the paper extent and also by the fact that time histories of the monitored quantities on the right side of the trolleybus and at running over the standardized obstacle with all the wheels and with only left wheels do not bring essential new pieces of knowledge for the evaluation of the impact of the change in the shock absorbers on the vehicle dynamic behaviour. Time histories of the dynamic forces acting in the centre air spring, time histories of the forces acting in the centre shock absorbers and time histories of the forces acting in the centre radius rods when simulating drives are given in Fig. 5 and 6. Extreme values taken from time histories of the monitored quantities are given in Table 1. Complete results are given in [4].
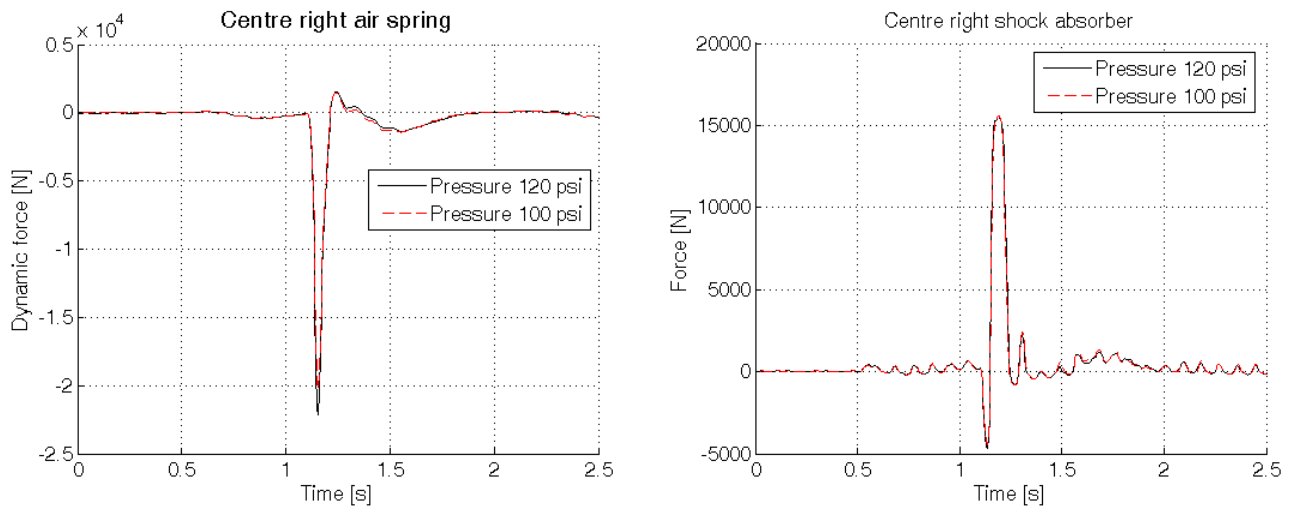

Fig. 5. Time histories of dynamic forces acting in the centre right air spring before axle (left) and of forces acting in the centre right shock absorber before axle (right).

Signs of the monitored quantities in air springs and shock absorbers and of axial forces acting in radius rods of the articulated trolleybus axles (Table 1 and graphs in Fig. 5 and 6) indicate acting of adjoining constructional parts (i.e. front body chassis, rear body chassis and axles) on those suspensions elements (e.g. minus sign at relative deflection of air spring 
corresponds to its compression, plus sign at the force acting in the shock absorber corresponds to its rebound, etc.).

Table 1. Extreme values of the monitored quantities at running over the standardized obstacle with the right wheels.

\begin{tabular}{|c|c|c|c|c|}
\hline $\begin{array}{c}\text { Monitored } \\
\text { quantity }\end{array}$ & $\begin{array}{l}\text { Placing of the element } \\
\text { of the axle suspension }\end{array}$ & Value & Pressure $120 \mathrm{psi}$ & Pressure $100 \mathrm{psi}$ \\
\hline \multirow{10}{*}{$\begin{array}{c}\text { Dynamic force } \\
\text { in the air spring } \\
{[\mathrm{kN}]}\end{array}$} & \multirow[t]{2}{*}{ Front right } & $\min$ & -19.2 & -17.3 \\
\hline & & $\max$ & 3.6 & 3.4 \\
\hline & \multirow[t]{2}{*}{ Centre right before axle } & $\min$ & -22.1 & -20.3 \\
\hline & & $\max$ & 1.6 & 1.4 \\
\hline & \multirow[t]{2}{*}{ Centre right behind axle } & $\min$ & -19.3 & -17.6 \\
\hline & & $\max$ & 1.6 & 1.4 \\
\hline & \multirow[t]{2}{*}{ Rear right before axle } & $\min$ & -22.2 & -20.2 \\
\hline & & $\max$ & 2.2 & 2.0 \\
\hline & \multirow[t]{2}{*}{ Rear right behind axle } & $\min$ & -18.9 & -17.4 \\
\hline & & $\max$ & 2.2 & 2.0 \\
\hline \multirow{10}{*}{$\begin{array}{c}\text { Force in the } \\
\text { shock absorber } \\
{[\mathrm{kN}]}\end{array}$} & \multirow[t]{2}{*}{ Front right } & $\min$ & -3.1 & -2.9 \\
\hline & & $\max$ & 14.9 & 14.6 \\
\hline & \multirow[t]{2}{*}{ Centre right before axle } & $\min$ & -4.7 & -4.4 \\
\hline & & $\max$ & 15.6 & 15.6 \\
\hline & \multirow[t]{2}{*}{ Centre right behind axle } & $\min$ & -4.6 & -4.3 \\
\hline & & $\max$ & 15.6 & 15.6 \\
\hline & \multirow[t]{2}{*}{ Rear right before axle } & $\min$ & -4.4 & -4.1 \\
\hline & & $\max$ & 16.2 & 16.2 \\
\hline & \multirow[t]{2}{*}{ Rear right behind axle } & $\min$ & -4.3 & -4.0 \\
\hline & & $\max$ & 16.3 & 16.1 \\
\hline \multirow{12}{*}{$\begin{array}{c}\text { Axial force in } \\
\text { the radius rod } \\
{[\mathrm{kN}]}\end{array}$} & \multirow[t]{2}{*}{ Front upper right } & $\min$ & -19.3 & -17.3 \\
\hline & & $\max$ & 14.5 & 13.3 \\
\hline & \multirow[t]{2}{*}{ Front lower right } & $\min$ & -27.3 & -27.6 \\
\hline & & $\max$ & 48.1 & 45.0 \\
\hline & \multirow[t]{2}{*}{ Centre upper right } & $\min$ & -25.2 & -23.1 \\
\hline & & $\max$ & 30.0 & 27.4 \\
\hline & \multirow[t]{2}{*}{ Centre lower right } & $\min$ & -35.0 & -36.4 \\
\hline & & $\max$ & 38.3 & 38.1 \\
\hline & \multirow[t]{2}{*}{ Rear upper right } & $\min$ & -22.1 & -20.9 \\
\hline & & $\max$ & 24.9 & 23.5 \\
\hline & \multirow[t]{2}{*}{ Rear lower right } & $\min$ & -46.4 & -47.7 \\
\hline & & $\max$ & 50.1 & 48.9 \\
\hline
\end{tabular}

When comparing extreme values of time histories of the monitored quantities taking into account the lower tires inflating, the consequence of their smaller radial stiffness and damping is evident [4]. It manifests itself in smaller dynamic forces and relative deflections in the air springs (see Fig. 5) and in the axial forces acting in the radius rods of the axles (see Fig. 6). Impact of the lower tires inflating does not manifest itself in the forces acting in the shock absorbers (see Fig. 5). Generally, at lower tires inflating lower extreme forces act in the trolleybus chassis and thereby there are lower extreme values of stresses in the trolleybus chassis. 

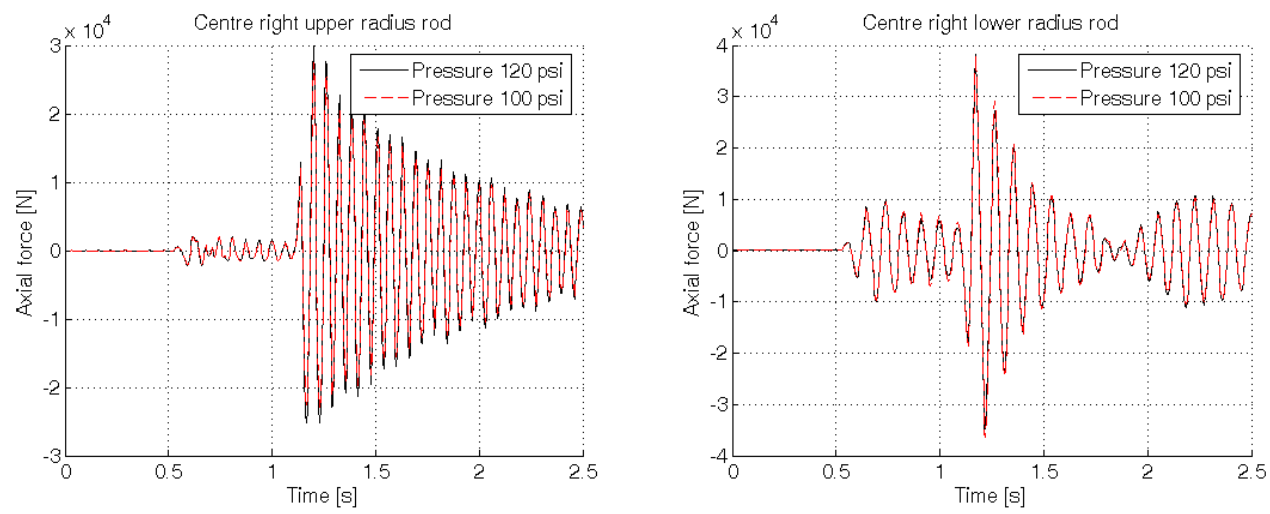

Fig. 6. Time histories of axial forces acting in the centre right upper radius rod (left) and in the centre right lower radius rod.

\section{Conclusions}

Influence of the lower tires inflating of the NEOPLAN DMA low-floor articulated trolleybus on forces acting in the trolleybus suspension elements and radius rods on the trolleybus chassis and axles is introduced in this paper. The impact of this change on these forces when running on an uneven test track was investigated using the multibody simulations. Multibody models of the trolleybus and simulations of its running were performed using the alaska simulation tool.

On the basis of the simulations results it was possible to state that the lower tires inflating is suitable because the maximum values of forces acting in the trolleybus suspension elements and radius rods decreased.

It would be possible to extend the simulations with the NEOPLAN DMA trolleybus multibody model by the simulations of other operational situations, the results of which would be interesting for the trolleybus producer. But due to the Neoplan USA Corporation having gone bankrupt further improvement of the NEOPLAN DMA trolleybus multibody model can be found only in the sphere of wishes.

Acknowledgement: The paper has originated in the framework of institutional support for the longtime conception development of the research institution provided by the Ministry of Industry and Trade of the Czech Republic.

\section{References}

1. G. Genta, L. Morello, The Automotive Chassis. Volume 2: System Design (Springer Science+Business Media B.V. 2009)

2. COSMOS/M, Finite Element Analysis System, User Guide, Version 2.5 (SRAC, Los Angeles, 1999)

3. M. Smola, J. Jankovec, M. Hejman, Static and Dynamic FEM Calculations of the NEOPLAN DMA Low-floor Articulated Trolleybus, Research Report VYZ 0693/2004 (ŠKODA VÝZKUM s.r.o. Plzeň, 2004)

4. P. Polach, Verified Multibody Model of the Empty NEOPLAN DMA Low-floor Articulated Trolleybus and Results of Running over the Large Road Unevenness Simulations, Research Report VYZ 0726/2004 (ŠKODA VÝZKUM s.r.o. Plzeň, 2004)

5. P. Polach, Manufacturing Technology, 15, 1, 77-86 (2015) 
6. K. Popp, W. Schiehlen, Ground Vehicle Dynamics (Springer-Verlag, Berlin Heidelberg, 2010)

7. T. D. Gillespie, S. M. Karamihas, Int. J. Heavy Veh. Syst. 7, 1, 52-63 (2000)

8. F. Vlk, Dynamics of motor vehicles (VLK Publishing House, Brno, in Czech, 2000)

9. M. Blundell, D. Harty, The Multibody Systems Approach to Vehicle Dynamics (Elsevier Butterworth-Heinemann, Oxford, 2004)

10. S. Hegazy, H. Rahnejat, K. Hussain, P. I. Mech. Eng. K-J. Mul. 213, 1, 19-31 (1999)

11. D. G. Rideout, Modern Mechanical Engineering, 2, 4, 176-189 (2012)

12. M.J. Thoresson, P.E. Uys, P.S. Els, J.A. Snyman, Math. Comput. Model. 50, 9-10, 1421-1436 (2009)

13. D. Margolis, D. Edeal, SAE Technical Paper 892488 (1989)

14. P. Michelberger, A. Keresztes, J. Bokor, P. Variaki, SAE Technical Paper 845120 (1984)

15. P.S. Els, P.E. Uys, J.A. Snyman, M.J. Thoresson, Math. Comput. Model. 43, 7-8, 787-801 (2006)

16. P. Eriksson, O. Friberg, Struct. Multidiscip. O. 20, 1, 67-75 (2000)

17. D. Andersson, P. Eriksson, Vehicle Syst. Dyn., Suppl. 41, 547-556 (2004)

18. I. Kowarska, J. Skarbek, K. Kuczek, T. Uhl, Journal of KONES Powertrain and Transport, 18, 4, 205-212 (2011)

19. I. Kowarska, J. Korta, K. Kuczek, T. Uhl, Shock Vib. 2014, ID 201952 (2014)

20. S. Hegazy, H. Rahnejat, K. Hussain, Vehicle Syst. Dyn. 34, 1, 1-24 (2000)

21. P. Polach, Manufacturing Technology, 13, 4, 515-520 (2013)

22. P. Maißer, C.-D. Wolf, A. Keil, K. Hendel, U. Jungnickel, H. Hermsdorf, P. A. Tuan, G. Kielau, O. Enge, U. Parsche, T. Härtel, H. Freudenberg, alaska, User Manual, Version 2.3 (Institute of Mechatronics, Chemnitz, 1998) 